\title{
ASSESSMENT OF PRODUCTION PROCESS CAPABILITY IN THE SERIAL PRODUCTION OF COMPONENTS FOR THE AUTOMOTIVE INDUSTRY
}

\author{
Jozef DOBRÁNSKY, Martin POLLÁK, Zigmund DOBOŠ \\ Technical University of Košice
}

\begin{abstract}
:
The article deals with the assessment of production process capability in the serial production of plastic components. The plastic component was used for analysis. Component is used in the automotive industry in car suspension shock absorbers. Assessing the capability of the product's manufacturing process is very important. The aim of the present paper is to measure the dimensional characteristics of a thermoplastic product as a monitored quality feature. The analyzed product is manufactured in an eightfold injection mold by injection technology. The products from each injection mold cavity were considered separately. Process capability was assessed using capability indices. Process variability and centering were evaluated. Based on the analysis we can say that the production process is in excellent condition.
\end{abstract}

Key words: production process, capability, automotive industry, plastic components

\section{INTRODUCTION}

Regulatory procedures serve to assess and improve the quality and stability of production processes. By assessing stability, it is possible to trace the production process from its input to its output $[5,12]$.

Quality serves as a simple and effective tool for acquiring or maintaining market shares in business in the current competitive market struggle. The implementation of statistical methods is a simple tool for monitoring the production process. They can be used to identify the causes of process instability. The process is effectively regulated and corrective measures are taken to increase process capability. At the same time, the quality and productivity of the entire production process is increased. For a comprehensive analysis of the potential problem, it is necessary to use as many statistical methods as possible $[1,7,9]$.

Statistical process control is a simple method used to control the quality of production processes. It is essential to use statistical methods. SPC is used to monitor and control the production process. Regulation consists of two distinct phases that logically follow one another. In the first stage, the specification of the individual elements of the production process is carried out. In the second phase, the process is used in production. The SPC method has many advantages over other quality control methods. The advantage of using SPC lies in the early detection and simultaneous prevention of possible problems and their correction $[2,18]$.

Capability of the production equipment characterizes the possibilities of the equipment and represents the adequate measure for its evaluation in purchase, after repairs and modernization and changes of the production assortment, etc. The information on capability of the production equipment and production process allow assessing of the extent of the variability of processes coming from other sources such as, for instance, influence of material, of operating, of maintenance, etc. Capability of measurement equipment characterizes its adequacy for measuring of particular quality character within the respective range. Its level may significantly influence the credibility of information on capability of the process or of the production equipment $[3,4,17]$.

The capability of the production process reflects its overall uniformity. It is also characterized and represented by process variability. The process capability is a statistical measure of the inherent process variability represented by the relevant characteristics. Uniform arrangements for assessing the capability of the production process have not yet been agreed. Sometimes the standard deviation is considered as an indicator of the process capability. In other cases, it is the range of the quality indicator or a multiple thereof based on intrinsic variability $[6,10,13]$.

The purpose of the present paper is to assess the capability of the manufacturing process in a particular manufacturing plant. To assess the capability of the production process, the product produced in series production was selected. Subsequently, qualitative characteristics were chosen and monitored.

\section{MATERIAL AND METHODS \\ Measured plastic product}

The measurements were performed on plastic product shown in Figure 1 (left). Component is used in the automotive industry in car suspension shock absorbers. The 
product is made from polymer composite material by injection molding technology in eightfold injection mold. Polyamide 66 (nylon) with glass fiber reinforced (30\%), heat stabilized, injection molding grade were used for production of this product. Material is resistant to the flexibility and the plastic coat itself has very good last. After the removal from the injection mold it goes to the finish where the rubber is deployed into the interior of the mold through vulcanization. Figure 1 (right) shows the dimensions that are measured and evaluated to monitor the manufacturing process capability $[8,15,16]$.
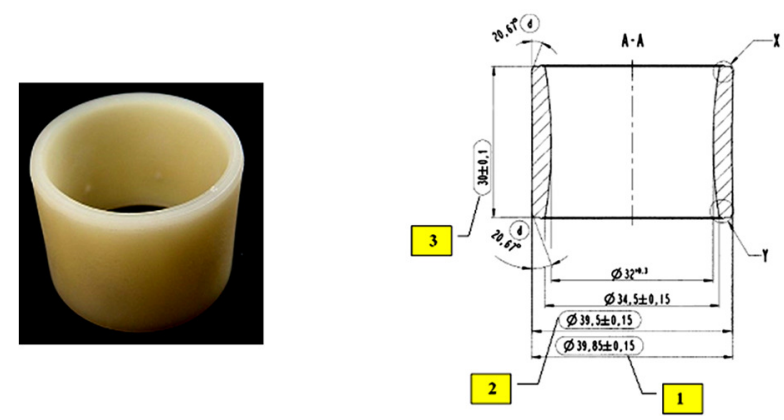

Fig. 1 Measured plastic product with measured dimensions

\section{Capability of production process}

Process capability index $C_{P}$ is a measure of potential ability of the process to assure the monitored quality character to be lying within the scope of tolerance limits. It characterizes the possibilities given by the process variability yet it does not specify the way of their actual use. It drawback rests in not taking into consideration the centre of distribution of the measure values with regards to the desired target value $T$ and requires definition of both tolerance limits. It is calculated according to the equation (1) [11]:

$$
C_{P}=\frac{U S L-L S L}{6 . \sigma}
$$

Capability index $C_{p k}$, contrary to index $C_{p}$, takes into consideration both variability and placement of the values of the monitored character within the tolerance zone. Thus it characterizes the actual process capability to respect the prescribed tolerance limits. At present this index ranks among the most frequently applied characteristics of the production process capability. It is calculated according to the equation (2) $[14,19,20]$ :

$$
C_{p k}=\min \left\{\frac{U S L-\mu}{3 \sigma}, \frac{\mu-L S L}{3 \sigma}\right\}=\min \left\{C_{p L}, C_{p U}\right\}
$$

\section{RESULTS AND DISCUSSION}

The chapter deals with the evaluation of production process capability. The process capability indices for the evaluation were used. Three length characteristics on the product were measured. As mentioned, the products were separately monitored from the eight cavities of the injection mold. A caliper with a range of $0-200 \mathrm{~mm}$ for measuring the length characteristics was used.

\section{Capability of process - Dimension 1 ( $\varnothing 39.85 \pm 0.15 \mathrm{~mm})$}

Table 1 shows the capability indexes for dimension 1 for all cavities. Index values are above 1.33. Based on the measured and evaluated characteristics, we can say that in this dimension the process is in excellent condition.
Table 1

\begin{tabular}{|c|c|c|c|c|c|c|}
\hline 宽 & $\begin{array}{l}\text { Max. value } \\
\text { (mm) }\end{array}$ & $\begin{array}{l}\text { Min. value } \\
(\mathrm{mm})\end{array}$ & $\begin{array}{c}\text { Average } \\
\text { value } \\
(\mathrm{mm})\end{array}$ & $\begin{array}{c}\text { St. } \\
\text { dev. }\end{array}$ & $C_{p}$ & $C_{p k}$ \\
\hline No. 1 & 39.75 & 39.74 & 39.7495 & 0.0022 & 22.827 & 7.533 \\
\hline No. 2 & 39.76 & 39.74 & 39.7448 & 0.0076 & 6.592 & 1.969 \\
\hline No. 3 & 39.79 & 39.76 & 39.7746 & 0.0080 & 6.276 & 3.121 \\
\hline No. 4 & 39.79 & 39.75 & 39.7768 & 0.0080 & 6.230 & 3.190 \\
\hline No. 5 & 39.79 & 39.75 & 39.7786 & 0.0091 & 5.493 & 2.878 \\
\hline No. 6 & 39.79 & 39.75 & 39.7735 & 0.0074 & 6.724 & 3.295 \\
\hline No. 7 & 39.79 & 39.75 & 39.7775 & 0.0069 & 7.276 & 3.759 \\
\hline No. 8 & 39.79 & 39.76 & 39.7735 & 0.0098 & 5.111 & 2.504 \\
\hline
\end{tabular}

Values of capability indexes for dimension 1

The histogram of frequencies and Shewart chart in Figure 2 show statistical manageability of the production process in case of cavity 2 . The average value amount to 39.7448 $\mathrm{mm}$ in case of this cavity. The finding was reflected even in the values of the process capability indexes. $C_{p}$ reached the value of 6.592 and $C_{p k}$ was 1.969. These findings proved that the production process is in very good condition and the values of capability indexes reached far behind the highest possible limit for the capability assessment and centring of the process.

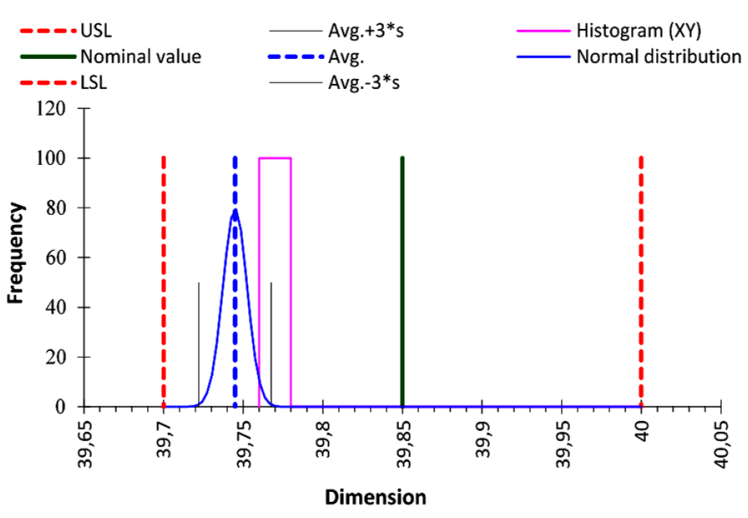

Fig. 2 Statistical manageability of the process - Dimension 1 Cavity 2

Capability of process - Dimension 2 ( $\varnothing 35.50 \pm 0.15 \mathrm{~mm})$

Table 2 represent values of capability index for dimension 2. The process capability indices again recorded high levels to 1.33. Based on the measured and evaluated characteristics, we can say that in this dimension the process is in excellent condition.

Table 2

Values of capability indexes for dimension 2

\begin{tabular}{ccccccc}
\hline \multirow{3}{*}{$\begin{array}{c}\text { Max. value } \\
(\mathbf{m m})\end{array}$} & $\begin{array}{c}\text { Min. value } \\
(\mathbf{m m})\end{array}$ & $\begin{array}{c}\text { Average } \\
\text { value } \\
(\mathbf{m m})\end{array}$ & St. dev. & $\mathbf{C}_{\mathbf{p}}$ & $\mathbf{C}_{\mathbf{p k}}$ \\
\hline No.1 & 39.58 & 39.5 & 39.5372 & 0.0141 & 3.534 & 2.658 \\
No. 2 & 39.56 & 39.53 & 39.5482 & 0.0095 & 5.281 & 3.584 \\
No. 3 & 39.56 & 39.52 & 39.5493 & 0.0107 & 4.690 & 3.149 \\
No. 4 & 39.59 & 39.52 & 39.5425 & 0.0138 & 3.621 & 2.595 \\
No.5 & 39.59 & 39.53 & 39.5570 & 0.0142 & 3.527 & 2.187 \\
No.6 & 39.58 & 39.53 & 39.5495 & 0.0125 & 3.999 & 2.679 \\
No. 7 & 39.58 & 39.52 & 39.5495 & 0.0167 & 2.990 & 2.004 \\
No.8 & 39.59 & 39.5 & 39.5512 & 0.0144 & 3.462 & 2.280 \\
\hline
\end{tabular}

The histogram of frequencies and Shewart chart in Figure 3 show statistical manageability of the production process in case of cavity 7. 
The histogram of frequencies and Shewart chart in Figure 3 show statistical manageability of the production process in case of cavity 7. The average value amount to $39.5495 \mathrm{~mm}$. The finding also was reflected in the values of the process capability indexes. $C_{p}$ reached the value of 2.990 and $C_{p k}$ was 2.004. These findings proved that the production process is in very good condition and is very well centred.

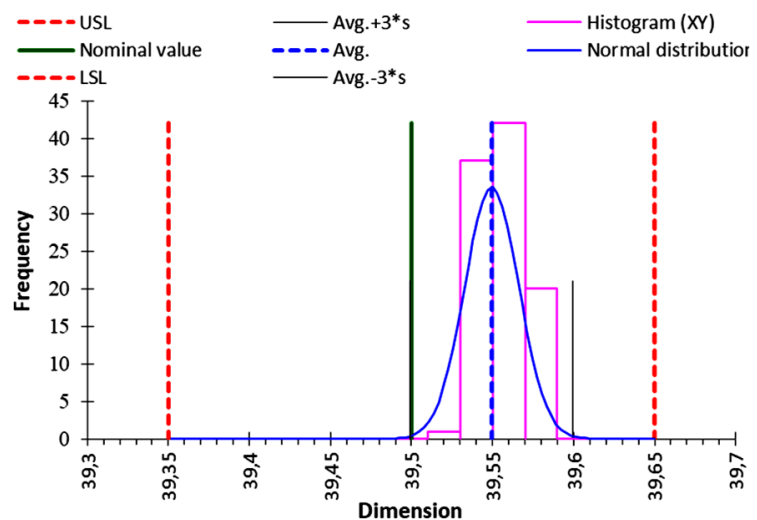

Fig. 3 Statistical manageability of the process - Dimension 2 Cavity 7

\section{Capability of process - Dimension $3(\varnothing 30.00 \pm 0.10 \mathrm{~mm})$}

Table 3 represent values of capability index for dimension 3 . The process capability indices again recorded high levels to 1.33. Based on the measured and evaluated characteristics, we can say that in this dimension the process is in excellent condition.

Table 3

Values of capability indexes for dimension 3

\begin{tabular}{|c|c|c|c|c|c|c|}
\hline \multirow{2}{*}{} & $\begin{array}{c}\text { Max. } \\
\text { value } \\
(\mathbf{m m})\end{array}$ & $\begin{array}{c}\text { Min. } \\
\text { value } \\
(\mathbf{m m})\end{array}$ & $\begin{array}{c}\text { Average } \\
\text { value } \\
(\mathbf{m m})\end{array}$ & St. dev. & $\mathbf{C}_{\mathbf{p}}$ & $\mathbf{C}_{\mathbf{p k}}$ \\
\hline No. 1 & 30.01 & 30.00 & 30.0065 & 0.0048 & 6.954 & 6.502 \\
\hline No. 2 & 30.01 & 30.00 & 30.0038 & 0.0049 & 6.833 & 6.573 \\
\hline No. 3 & 30.01 & 30.00 & 30.0046 & 0.0050 & 6.655 & 6.348 \\
\hline No. 4 & 30.01 & 30.00 & 30.0054 & 0.0050 & 6.655 & 6.295 \\
\hline No. 5 & 30.01 & 29.99 & 30.0043 & 0.0052 & 6.442 & 6.165 \\
\hline No. 6 & 30.01 & 29.98 & 30.0054 & 0.0058 & 5.788 & 5.475 \\
\hline No. 7 & 30.01 & 29.98 & 30.0052 & 0.0056 & 5.961 & 5.651 \\
\hline No. 8 & 30.01 & 30.00 & 30.0063 & 0.0049 & 6.870 & 6.437 \\
\hline
\end{tabular}

Based on the measured values the histogram of the frequencies of the measured values and the Shewart charts for the assessment of statistical manageability of the process were drawn (Figure 4).

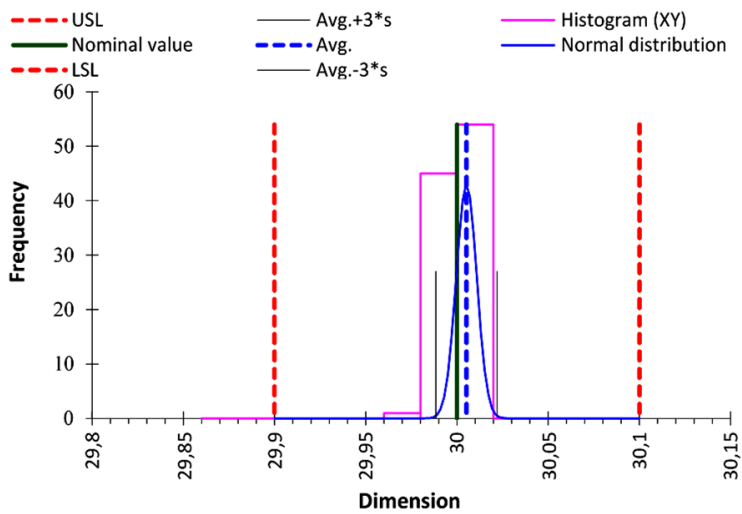

Fig. 4 Statistical manageability of the process - Dimension 3 Cavity 6
In case of cavity 6 the average value of the measurement was $30.0054 \mathrm{~mm}$. $C_{p}$ reached the value of 5.788 and $C_{p k}$ was 5.475. These findings proved that the production process is in a very good condition and is very well centred.

\section{CONCLUSION}

Quality and stability of the production process are notions associated with the regulation procedures. In simple terms, the stability refers to the fact whether the value prescribed during input can be observed during output. Capability of the process refers to the process uniformity. Its output extent is usually represented by the process variability. Capability of the process is statistical measure of the inherent variability of the process for the respective characteristics. The process capability measure has not been agreed on up to present. At times the standard deviation $\sigma$ or range of quality indicator or their multiple based upon the inherent variability are considered to be the capability measure. Occasionally, it is a combined value of the component induced by the inherent variability and of the component induced by inconsiderable and determinable causes. Paper focuses on the assessment of the production process in the production of plastic product intended for the automotive industry. Process capability indexes and process capability histograms were used as a tool for monitoring the production process. During the evaluation we had the opportunity to record the same cases. High capability index values were recorded at all dimensions. All products manufactured in seven different injection mold cavities showed high capability indices. Based on the measured characteristics, it can be say that the process is a very good mastered state. The customer thus has evidence that the product was created under stable conditions ensuring compliance with the prescribed quality criteria in the production process.

\section{ACKNOWLEGEMENT}

This research has been elaborated in the framework of the projects KEGA no. 006TUKE-4/2017 Innovation of Laboratory quality control of components for the automotive and allied industries within the framework of the integration of advanced cognitive operations into education.

\section{REFERENCES}

[1] H. Alavi and P. Habek. "Addressing Research Design Problem in Mixed Methods Research". Management Systems in Production Engineering, vol. 21, pp. 62-66, Mar 2016.

[2] W. Bialy and J. Ruzbarsky. "Breakdown Cause and Effect Analysis. Case Study". Management Systems in Production Engineering, vol. 26, pp. 83-87, Jun 2018.

[3] P. Baron, M. Kocisko, L. Blasko and P. Szentivanyi. "Verification of the operating condition of stationary industrial gearbox through analysis of dynamic signal, measured on the pinion bearing housing". Measurement, vol. 96, pp. 2433, Jan. 2017.

[4] P. Bozek, P. Pokorny, J. Svetlik, A. Lozhkin and I. Arkhipov. "The calculations of Jordan curves trajectory of the robot movement". International Journal of Advanced Robotic Systems, vol. 13, Oct. 2016. 
[5] D. de-Felipe and E. Benedito. "Monitoring High Complex Production Processes Using Process Capability Indices". International Journal of Advanced Manufacturing Technologies, vol. 93, pp. 1257-1267, Oct. 2017.

[6] J. Dobránsky, A. Panda and D. Mandulák. Quality Monitoring in Production of the Parts in Automotive Industry. Ludenscheid: RAM-Verlag, 2015, 195.

[7] D. Duplakova, L. Knapcikova, M. Hatala and E. Szilagyi. "Mathematical Modeling of Temperature Characteristics of RFID Tags with their Subsequent Application in Engineering Production". TEM Journal-Technology Education Management Informatics, vol. 5, pp. 411-416, Nov. 2016.

[8] T. Holota, J. Hrubec, M. Kotus, M. Holiencinova and E. Caposova. "The Management of Quality Costs Analysis Model". Serbian Journal of Management, vol. 11, pp. 119127, 2016.

[9] C. Ngaowthong, M. Boruvka, L. Behalek, P. Lenfeld, M. Svec, R. Dangtungee, S. Siengchin, SM. Rangappa and J. Parameswaranpillai. "Recycling of sisal fiber reinforced polypropylene and polylactic acid composites: Thermomechanical properties, morphology, and water absorption behavior". Waste Management, vol. 97, pp. 71-81, Sep. 2019.

[10] J. Kascak, P. Baron, M. Teliskova, J. Zajac, J. Torok and J. Husar. "Implementation of Augmented Reality into the Training and Educational Process in Order to Support Spatial Perception in Technical Documentation". 6th IEEE International Conference on Industrial Engineering and Applications. 2019, pp. 583-587.

[11] I. Kovac, R. Mikus, R. Drlicka and J. Zitnansky. "Boron Effect on Mechanical Properties and Structure of Steel STN 41 5230 Surface Layer". Advanced Materials Research, vol. 801, pp. 123-129, 2013.

[12] G. Kovacic and Z. Kondic. "Statistical Analysis of Stretch Film Production Process Capabilities". Technicki GlasnikTechnical Journal, vol. 6, pp. 191-198, Dec. 2012.

\section{Jozef Dobránsky}

ORCID ID: 0000-0002-1728-1799

Technical University of Košice

Faculty of Manufacturing Technologies with a seat in Prešov Department of Automotive and Manufacturing Technologies Štúrova 31, 08001 Prešov, Slovak Republic

e-mail: jozef.dobransky@tuke.sk

\section{Martin Pollák}

ORCID ID: 0000-0002-3794-3745

Technical University of Košice

Faculty of Manufacturing Technologies with a seat in Prešov Department of Computer Aided Manufacturing Technologies Štúrova 31, 08001 Prešov, Slovak Republic e-mail: martin.pollak@tuke.sk

\section{Zigmund Doboš}

Technical University of Košice

Faculty of Manufacturing Technologies with a seat in Prešov Department of Technical Systems Design and Monitoring Štúrova 31, 08001 Prešov, Slovak Republic e-mail: doboszig@gmail.com
[13] KP Lin, CM Yu and KS Chen. "Production Data Analysis System Using Novel Process Capability Indices-Based Circular Economy". Industrial Management \& Data Systems, vol. 119, pp. 1665-1668, Sep. 2019.

[14] P. Monka, K. Monkova, V. Modrak, S. Hric and P. Pastucha. "Study of a Tap Failure at the Internal Threads Machining". Engineering Failure Analysis, vol. 100, pp. 25-36, Jun 2019.

[15] A. Panda, S. Olejarova, J. Valicek and M. Harnicarova. "Monitoring of the condition of turning machine bearing housing through vibrations". International Journal of Advanced Manufacturing Technology, vol. 97, pp. 401-411, Jul 2018.

[16] A. Panda, K. Dyadyura, J. Valicek, M. Harnicarova, J. Zajac, V. Modrak, I. Pandova, P. Vrabel, E. Novakova-Marcincinova and Z. Pavelek. "Manufacturing Technology of Composite Materials-Principles of Modification of Polymer Composite Materials Technology Based on Polytetrafluoroethylene". Materials, vol. 10, pp. Apr. 2017.

[17] P. Polak, R. Drlicka and J. Zitnansky. "Capability Assessment of Measuring Equipment Using Statistic Method". Management Systems in Production Engineering, vol. 16, pp. 184-186, 2014.

[18] M. Seidl, J. Bobek, P. Lenfeld and L. Behalek. "Melt Flow Behaviour of Composite Materials with Natural Animal Fillers". AD Alta-Journal of Multidisciplinary Research, vol. 1, pp. 158-160, 2011.

[19] J. Svetlik and P. Demec. "Principles of modular architecture in the manufacturing technology". III Central European Conference on Logistics, 2013, pp. 105-112.

[20] J. Torok, M. Kocisko, M. Teliskova and M. Janak. "Increasing of the Work Productivity of CMM Machine by Applying of Augmented Reality Technology". MATEC Web of Conferences, 2016. 